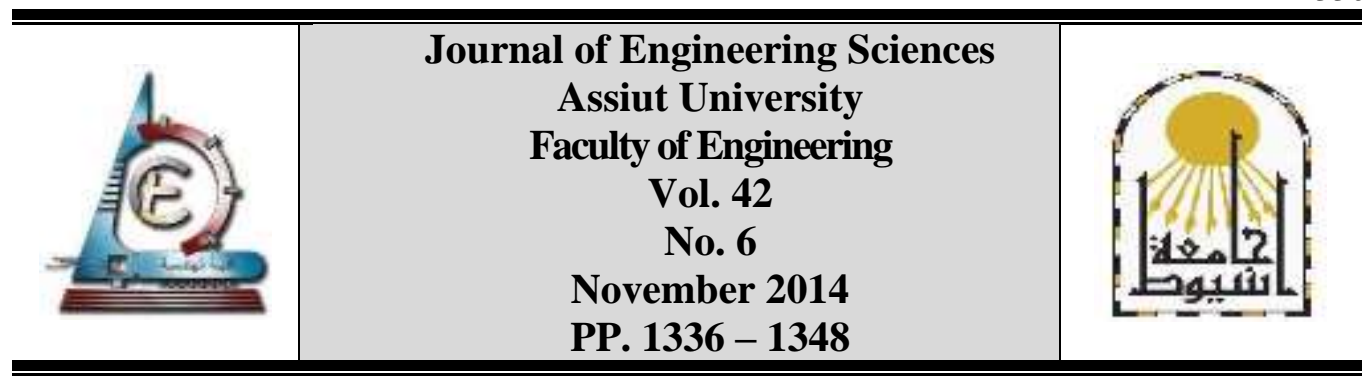

\title{
2D PLAXIS FINITE ELEMENT MODELING OF ASPHALT- CONCRETE PAVEMENT REINFORCED WITH GEOGRID
}

\author{
Hamdy Faheem * and Ahmed Mohamed Hassan \\ Faculty of Eng., Minia University, Civil Engineering Department, Egypt
}

(Received 30 November 2014; Accepted 30 December 2014)

\begin{abstract}
Geogrid-reinforcement is often used in conjunction with unbound base layers to enhance flexible pavements performance. This paper presents an axisymmetric finite element (FE) model to analyze the behavior of unreinforced and geogrid reinforced bituminous pavement subjected to static and dynamic loadings. The model was loaded with an incremental loading and the critical pavement responses such as effective stress and vertical surface deflection were determined for unreinforced and geogrid reinforced flexible pavement. The results indicated that during static loading, a moderate effect on the pavement behavior was observed due to the reinforcing geogrid layer. This effect was not noted in case of dynamic loading. The effect of dynamic loading frequency on pavement settlement was significant especially for high loading amplitudes. The results also showed no significant improvement in pavement system behavior was obtained by adding another layer of geogrid reinforcement.
\end{abstract}

Keywords: Geogrid, Pavement Performance, Plaxis Program, FE Analysis; Flexible Pavement; Reinforced Pavement; Dynamic Loading

\section{Introduction}

In the last few decades, geosynthetic reinforcement, particularly high modulus polymeric geogrid, has been increasingly utilized within pavement layers to improve the structural performance of both newly constructed and rehabilitated flexible pavement. Besides reducing the rutting strain, geogrids also resist fatigue (horizontal) strain through the tensioned membrane effect, induced in the bituminous concrete layer [1]. The Geogridreinforcement layer is usually placed between the sub-base and sub grade interface or between the base course and sub-base. Due to the wide application of this technique, many experimental and analytical studies have been conducted to assess and potentially quantify the improvements associated with geogrid base reinforcement of roadways. The use of geogrid reinforcement in roadway applications started in the 1970s. Since then, the technique of geogrid reinforcement has been increasingly used and many studies have been performed to investigate its behavior in roadway applications [2, 3, 4, and 5].

* Corresponding author.

Email address: drhamdyfaheem@gmail.com 
Numerous researchers studied the impact of geosynthetic reinforcement over structural performance of paved roads through laboratory, field, and numerical modeling methods. Pandey et al. [6] performed a series of FE simulations to evaluate the benefits of integrating a high modulus geogrid as reinforcement into the pavement layers. Their study presents a two dimensional axisymmetric FE model that analyzes the behavior of unreinforced and geogrid reinforced bituminous pavement subjected to static and dynamic loading conditions. The results showed that placing geogrid reinforcement at the basebituminous concrete interface leads to the highest reduction in fatigue (horizontal) strain. The highest decrease of vertical strain occurs when the reinforcement is placed at the interface of base and sub grade layers. Barksdale, Brown and Chan [7] compared the structural performance of unreinforced and geogrid reinforced pavement subjected on cyclic loading condition through laboratory experimentation. Performance characterization of the unreinforced and geogrid reinforced pavement was carried out on the basis vertical permanent deformation. The results of the study indicated that for a stronger pavement, the stiff geogrid at the bottom of the granular base did not produce any significant improvement. Their results further indicated that placing the geogrid in the middle and bottom of the base layers, despite its lower stiffness, resulted in better performance against permanent deformation than the use of a geotextile. Numerical simulation carried out by them using FE analysis techniques showed that the benefits of geosynthetic reinforcements are more pronounced for weaker subgrades. Virgile et al. [8] studied the flexural behavior of bi-layer bituminous system reinforced with geogrid through laboratory experiments. Geogrid was placed at the interface of bituminous layer. The laboratory study showed that the reinforced system improved the resistance to repeated load cycles by $66 \%$ to $100 \%$ and delayed the inversion from decreasing to increasing rate of the permanent deformation evolution curve. However, this study did not include the effect of geogrids on fatigue resistance of asphalt layers. Dondi [9] used the FE program ABAQUS to model a geosynthetic reinforced flexible pavement. Three dimensional static analysis was carried out using linear and nonlinear constitutive material models. Bituminous concrete layer and geosynthetic reinforcement were modeled using a linear elastic material model based on Hook's law while Drucker-Prager and Cam Clay material models were used to model base course and subgrade layers. The results of their study indicated $15-20 \%$ reduction in vertical displacement under the load in reinforced section and 2-2.5 times increase in fatigue life of reinforced sections compared to unreinforced sections. Moayedi et al. [10] studied the effect of geogrid reinforcement location in paved road improvement using axisymmetric pavement response model developed through the FE program PLAXIS. Bituminous concrete layer and geogrid were modeled as a linear elastic isotropic material while the Moho-Coulomb material model was used to simulate granular layers. Pavement responses were determined under static loading condition. They showed that the geosynthetic reinforcement placed at the bottom of bituminous concrete layer leads to the highest reduction in vertical pavement deflection. Miura et al. [11] performed a FE analysis on reinforced and unreinforced pavement sections. They compared the results of the FE analysis with the experimental measurements on similar sections. The results indicated that the prediction of FE analysis was not in agreement with the behavior observed in the tests. The predicted reduction in surface displacements was $5 \%$ compared to an actual displacement reduction of $35 \%$ measured by the tests. Dondi [9] used ABAQUS software package to conduct a three dimensional FE analysis to model the geosynthetic reinforced pavements. The results of this study indicated that the use of the 
reinforcement resulted in an improvement in the bearing capacity of the subgrade layer and a reduction in the shear stresses and strains on top of it. In addition, the vertical displacement was also reduced by 15 to $20 \%$ due to the intrusion of geosynthetic reinforcement. Wathugala et al. [12] used ABAQUS FE software package to formulate the FE model for pavements with geogrid reinforced bases. The results of the analysis were compared with an unreinforced pavement sections at the same geometry and material properties. The comparisons indicated that the inclusion of geogrid reinforcement reduced the permanent deformations by $20 \%$ for a single load cycle. This level of improvement was related to the flexural rigidity of the geosynthetics caused by the model presentation used by the authors [3]. Leng and Gabr [13] conducted a numerical analysis using ABAQUS to investigate the performance of reinforced unpaved pavement sections. They reported that the performance of the reinforced section was enhanced as the modulus ratio of the aggregate layer to the subgrade decreased. The critical pavement responses were significantly reduced for higher modulus geogrid or better soil/aggregate-geogrid interface property. Nazzal et al. [14] developed a finite-element model with ABAQUS software package to investigate the effect of placing geosynthetic reinforcement within the base course layer on the response of a flexible pavement structure. Finite-element analyses were conducted on different unreinforced and geosynthetic reinforced flexible pavement sections. The results of the FE analyses showed that the geosynthetic reinforcement reduced the lateral strains within the base course and subgrade layers. Furthermore, the inclusion of the geosynthetic layer resulted in a significant reduction in the vertical and shear strains at the top of the subgrade layer. The improvement of the geosynthetic layer was found to be more pronounced in the development of the plastic strains rather than the resilient strains. The reinforcement benefits were enhanced as its elastic modulus increased.

Many researchers believe that geogrid should be placed at the top of base course while others have found that geogrid should be placed at the base-subgrade interface. In the present study a FE simulation of an asphalt-concrete typical pavement section reinforced with geogrid was carried out using 2D Plaxis FE program. The model was loaded with an axle load of increasing from $50 \mathrm{kPa}$ to $600 \mathrm{kPa}$. Effect of a geogrid layer placed under the pavement layer was investigated under static and dynamic load.

\section{Development of the numerical model}

A typical reinforced pavement system consists of hot-mix asphalt layer, base course layer, sub-base layer and subgrade layer as well as reinforcement layers. The pavement is modeled as a multilayer structure subjected to static and dynamic loading. The model was developed using 2-D Plaxis FE software to analyze the unreinforced and geogrid reinforced flexible pavement structure [15]. The load is applied as uniform pressure acting on a circular area of radius $0.2 \mathrm{~m}$. Applied pressure values were: 50, 100, 200, 300, 400, 500, and $600 \mathrm{kPa}$. Linear elastic materials were assigned to the AC and the geogrid layers whereas the base course and the sub-base layers were modeled using Mohr-coulomb constitutive model.

An axisymmetric model was utilized in the analysis using 15-noded structural solid element with medium refinement. Axisymmetric modeling was chosen in this study because it could simulate circular loading and did not require excessive computational time under dynamic loading $[2,16]$.

Figures 1 through 3 show the model considered where total thickness of the pavement is $0.8 \mathrm{~m}$. The sand subgrade soil of thickness $1.2 \mathrm{~m}$ is overlaid by a $0.40 \mathrm{~m}$ layer of crushed 
gravel as sub-base, $0.30 \mathrm{~m}$ crushed gravel as base course and $0.1 \mathrm{~m}$ asphalt concrete on top. The bottom of model was fixed in both vertical and horizontal directions. Both edges of the models were restricted against horizontal movement. Material parameters and constitutive models used are shown in Table (1) whereas Table (2) shows mechanical properties of geogrid reinforcement.

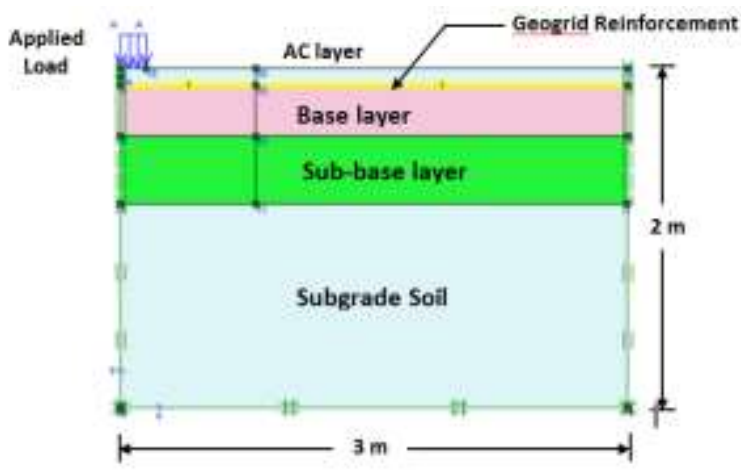

Fig. 1. FE axisymmetric model for unreinforced pavement.

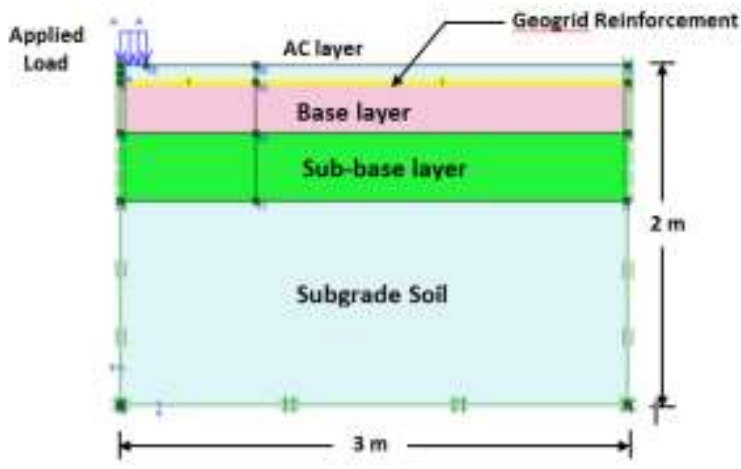

Fig. 2. FE axisymmetric model considered for one-layer reinforced pavement.

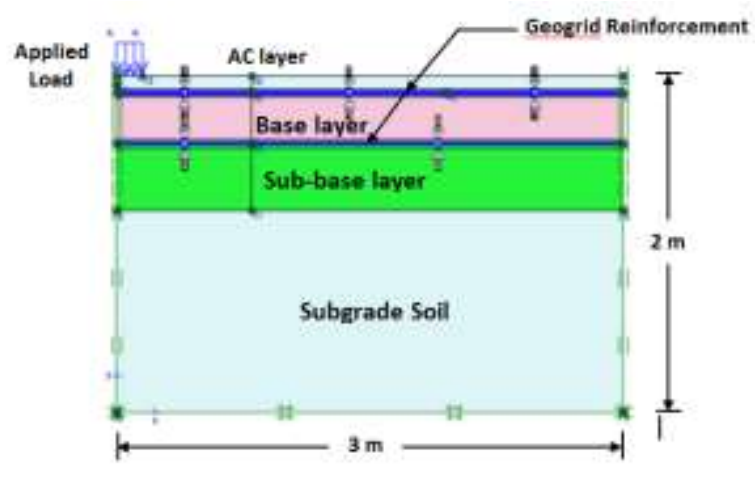

Fig. 3. FE axisymmetric model considered for two-layer reinforced pavement. 
Table 1.

Material properties

\begin{tabular}{|c|c|c|c|c|}
\hline Material & $\begin{array}{l}\text { Asphalt } \\
\text { Concrete }\end{array}$ & $\begin{array}{c}\text { Base } \\
\text { (Crushed } \\
\text { Stone) } \\
\end{array}$ & $\begin{array}{c}\text { Sub-base } \\
\text { (Crushed } \\
\text { Stone) }\end{array}$ & $\begin{array}{c}\text { Sub- } \\
\text { grade } \\
\text { ( Sand) }\end{array}$ \\
\hline Model & $\begin{array}{l}\text { Linear- } \\
\text { elastic }\end{array}$ & $\begin{array}{c}\text { Mohr- } \\
\text { Coulomb }\end{array}$ & $\begin{array}{c}\text { Mohr- } \\
\text { Coulomb }\end{array}$ & $\begin{array}{c}\text { Mohr- } \\
\text { Coulomb }\end{array}$ \\
\hline Thickness (m) & & & 0.40 & 1.20 \\
\hline Young's modulus ( KPa) & 0.10 & 0.30 & $50 \times 10^{3}$ & $20 \times 10^{3}$ \\
\hline Poisson's Ratio & $2100 \times 10^{3}$ & $100 \times 10^{3}$ & 0.30 & 0.30 \\
\hline Dry density $\left(\mathrm{kN} / \mathrm{m}^{3}\right)$ & 0.45 & 0.35 & 18.0 & 17.0 \\
\hline Saturated density & 20.0 & 20.0 & 20.0 & 18.0 \\
\hline$\left(\mathrm{kN} / \mathrm{m}^{3}\right)$ & - & 22.00 & 20 & 0 \\
\hline Cohesion $\left(\mathrm{kN} / \mathrm{m}^{2}\right)$ & - & 30 & 40 & 35 \\
\hline Friction angle (degree) & - & 43 & 14 & 5 \\
\hline Dilatation angle (degree) & - & 13 & 1.000 & 1.000 \\
\hline $\mathrm{k}_{\mathrm{x}}[\mathrm{m} / \mathrm{day}]$ & - & 1.000 & 1.000 & 1.000 \\
\hline $\mathrm{k}_{\mathrm{y}}[\mathrm{m} / \mathrm{day}]$ & - & 1.000 & & \\
\hline
\end{tabular}

Table 2.

Mechanical properties of geogrid reinforcement

\begin{tabular}{|c|c|c|}
\hline Material & Elastic axial stiffness (KN/m) & Poisson' ratio \\
\hline Geogrid 1 & 213 & 0.25 \\
\hline Geogrid 2 & 534 & 0.25 \\
\hline Geogrid 3 & 950 & 0.25 \\
\hline
\end{tabular}

\section{Results and analysis}

\subsection{Static loading}

\subsubsection{One layer of geogrid}

In this section static loading condition is presented for both unreinforced and geogridreinforced base. Applied pressure ranged from $50 \mathrm{kPa}$ to $600 \mathrm{kPa}$ and geogrid was placed at the interface of asphalt concrete layer and base course. Critical pavement responses i.e. effective stress and total vertical displacement of unreinforced and geogrid reinforced pavements are determined under for each static loading value.

Figures 4 and 5 illustrate the vertical displacement profile for applied load of $400 \mathrm{kPa}$ for case of unreinforced pavement and reinforced pavement with one layer of geogrid of elastic axial stiffness of $950 \mathrm{kPa}$ placed under AC layer. It may be observed that a significant decrease in vertical settlement obtained for reinforced pavement. Maximum vertical displacement is $6 \times 10^{-3} \mathrm{~m}$, for case of unreinforced pavement, while it is $3.2 \times 10^{-3} \mathrm{~m}$ for reinforced base. 


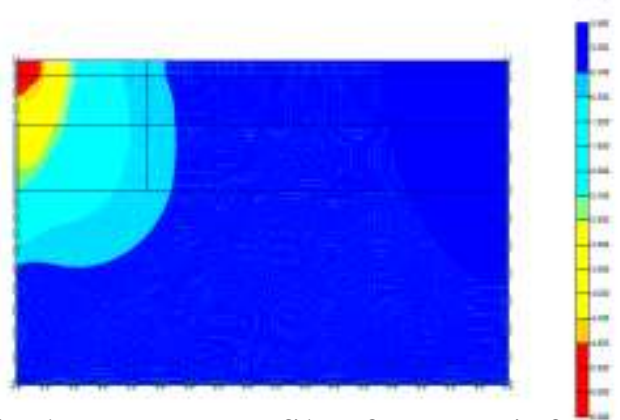

Fig. 4. Vertical displacement profile for unreinforced pavement (applied pressure $=400 \mathrm{kPa}$ )

Fig. 5. Vertical displacement profile for one-layer reinforced pavement (geogrid elastic axial stiffness $=950 \mathrm{kN} / \mathrm{m}$, applied pressure $=400 \mathrm{kPa}$ ).

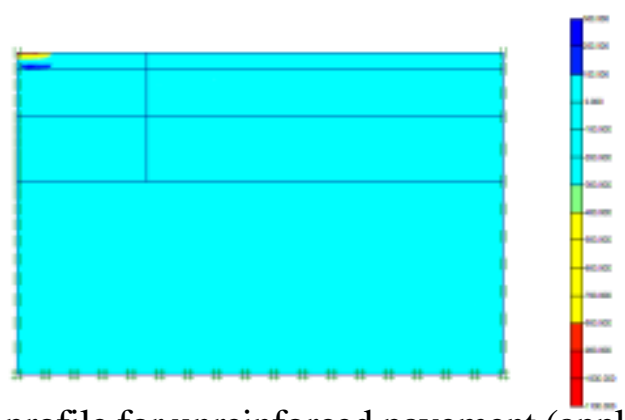

Fig. 6. Effective stresses profile for unreinforced pavement (applied pressure $=400 \mathrm{kPa}$ ).

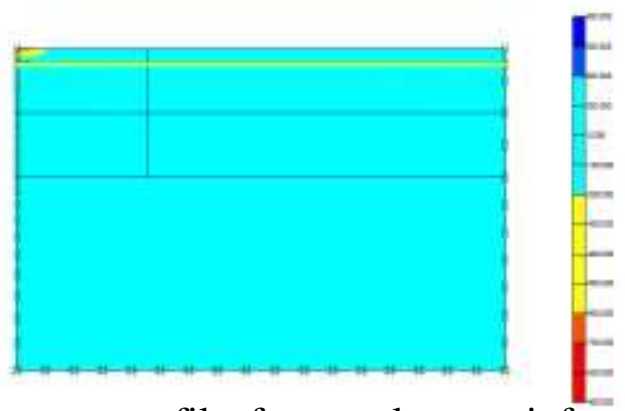

Fig. 7. Effective stresses profile for one-layer reinforced pavement (geogrid elastic axial stiffness $=950 \mathrm{kN} / \mathrm{m}$, applied pressure $=400 \mathrm{kPa}$ ). 
Figures 6 and 7 illustrate the effective stresses profiles for applied pressure of $400 \mathrm{kPa}$ for case of unreinforced pavement and reinforced pavement with one layer of geogrid of elastic axial stiffness $=950 \mathrm{kN} / \mathrm{m}$ placed under AC layer. These figures depict that for unreinforced pavement, maximum effective stress is significantly higher $(1100 \mathrm{kPa})$ compared with that for case of reinforced pavement $(900 \mathrm{kPa})$.

\subsubsection{Two layers of geogrid}

Effect of applying two layers of geogrid reinforcement is shown in Figure 8 which illustrates the total vertical displacement profiles for axle applied pressure of $400 \mathrm{kPa}$. The two layers of geogrid are of elastic axial stiffness $=950 \mathrm{kN} / \mathrm{m}$. One of two layers is placed under AC layer while the other is placed under base course layer. It may be noted that no significant in vertical displacement is gained by placing two layers of geogrid. Values of maximum vertical displacement are close to those in case of one-layer reinforced pavement.

Figures 9 illustrate the total effective stresses profiles for applied load of $400 \mathrm{kPa}$ for case of two layers of geogrid of elastic axial stiffness $=950 \mathrm{kN} / \mathrm{m}$. It is clear that no significant reduction in effective stresses is gained by adding the second layer of geogrid.

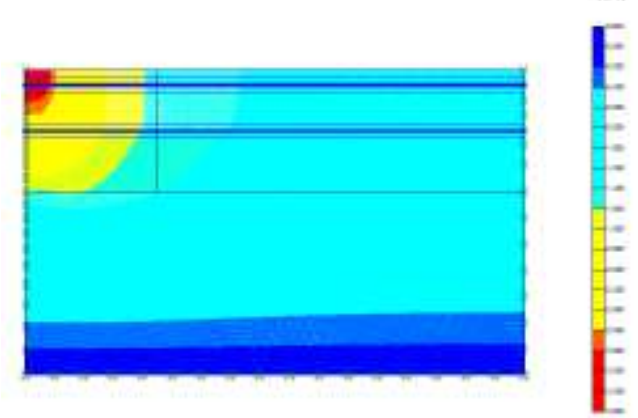

Fig. 8. Total vertical displacement profile for two-layer reinforced pavement (geogrid elastic axial stiffness $=950 \mathrm{kN} / \mathrm{m}$, applied pressure $=400 \mathrm{kPa}$ ).

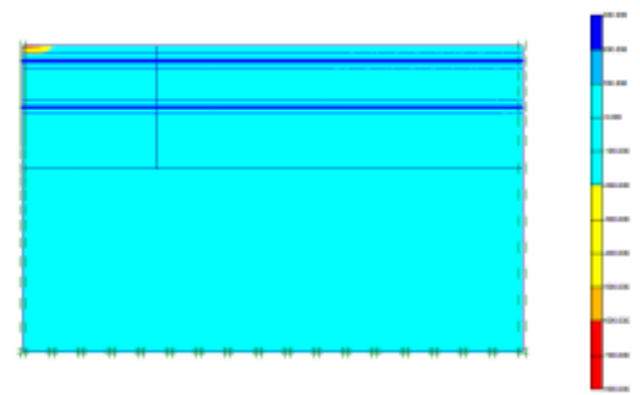

Fig. 9 Total effective stress profile for two-layer reinforced pavement (geogrid elastic axial stiffness $=950 \mathrm{kN} / \mathrm{m}$, applied pressure $=400 \mathrm{kPa}$ ).

\subsubsection{Comparisons between unreinforced and reinforced pavement structure:}

\subsubsection{Effect of geogrid reinforcement elastic axial stiffness}

Elastic axial stiffness (tensile modulus) is one of the most important properties of geogrid reinforcement which have significant influence on the performance of pavement structure. In this study, three types of geogrid reinforcement were analyzed to examine the influence of tensile modulus on the behavior of pavement system. The geogrid's elastic modulus was taken as its tensile modulus (at 5\% strain) per unit width divided by its 
thickness. Regardless of the number of reinforcement layers, the pavement with geogrid reinforcement of higher tensile modulus has a slightly higher effective stress than that with lower elastic modulus as shown in Figure 10. It can be observed that effect of geogrid elastic axial stiffness is not significant.

Figure 11 shows the vertical settlement response of unreinforced and reinforced pavement with different elastic modulus values. It may be noted that no geogrid reinforcement moderately reduces vertical settlement of pavement system. The influence of elastic modulus is not, however, significant.

\subsubsection{Effect of number of geogrid reinforcement}

Figures 12 and 13 show comparison between pavement system behavior for three cases: unreinforced pavement, one-layer reinforced pavement, and two-layer reinforced pavement. The three cases are compared in regards of effective stress and vertical settlement responses. It may be noted that no significant effect of number of geogrid layers is obtained.

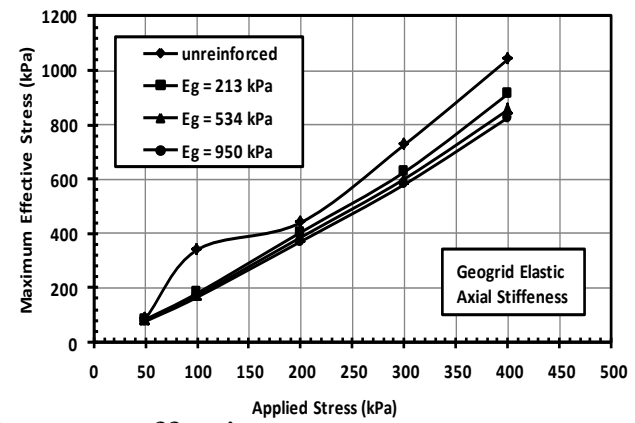

Fig. 10. Maximum effective stresses versus applied pressure for unreinforced and one-layer reinforced systems.

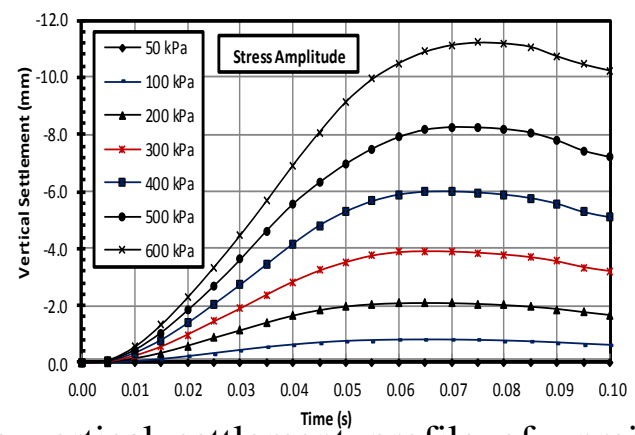

Fig. 11. Maximum vertical settlement profile of unreinforced and one-layer reinforced system

\subsection{Dynamic loading}

Dynamic analysis is performed using Plaxis software (Plaxis B. V. (2004)). A half-sine pulse dynamic load was applied with amplitudes 50, 100, 200, 300, 400, 500, and $600 \mathrm{kPa}$. Figure 14 shows dynamic load sample pulse for case of duration time $=0.10 \mathrm{~s}$, frequency $=$ $5 \mathrm{~Hz}$ and load amplitude $=500 \mathrm{kPa}$. In reality the magnitude, shape, and duration of such a pulse may vary with the stiffness of pavement, wheel load magnitude, its speed, and the depth of the study point. The half-sine pulse is widely used by many researchers to simulate a moving load on pavement surface. Kazemien et al. (2010) evaluated the dynamic response of multilayer pavement system using half-sine load pulse of $0.03 \mathrm{sec}$ 
duration. Saad, Mitri and Poorooshasb (2006) used transitive triangular load pulse of 0.1 sec. duration corresponding to an average speed of around $20 \mathrm{mph}(32.14 \mathrm{~km} / \mathrm{h})$ with a peak pressure $550 \mathrm{kPa}$.

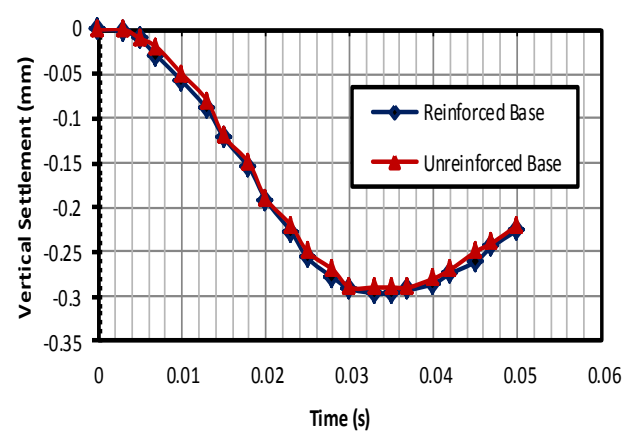

Fig. 12. Maximum effective stress profile for unreinforced, one-layer, and twolayers reinforced pavement systems.

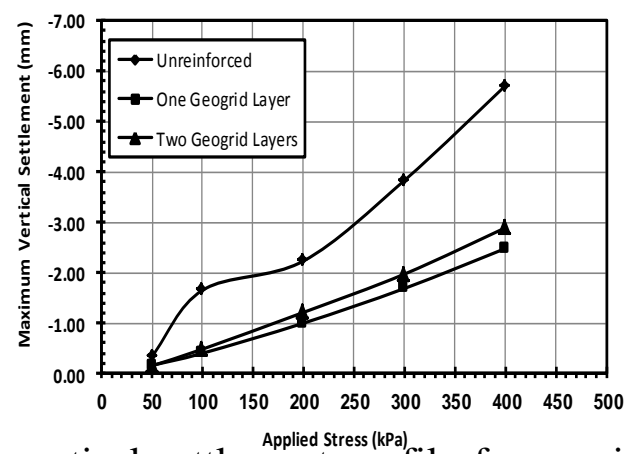

Fig. 13. Maximum vertical settlement profile for unreinforced, one-layer, and two-layers reinforced pavement systems.

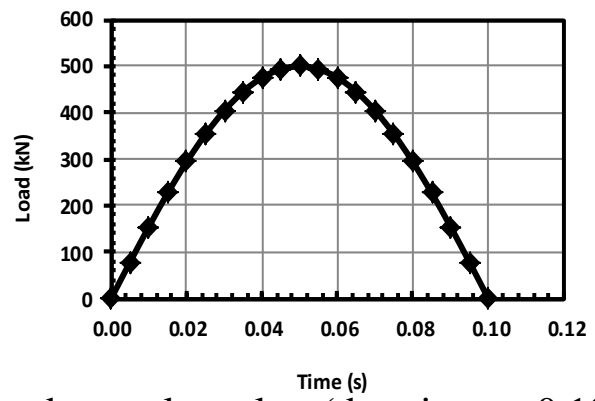

Fig. 14. Dynamic load sample pulse (duration $=0.10 \mathrm{~s}$, frequency $=5 \mathrm{~Hz}$, amplitude $=500 \mathrm{kPa})$. 


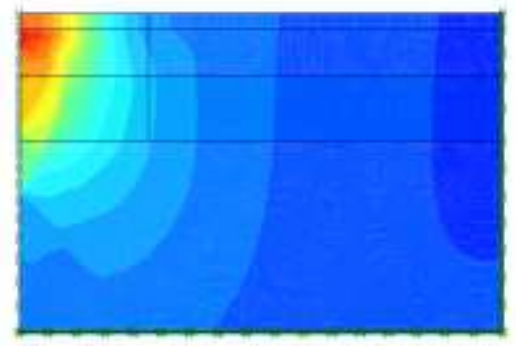

Fig. 15. Vertical settlement contours for load amplitude $400 \mathrm{kPa}, \mathrm{t}=0.05 \mathrm{~s}(\mathrm{f}=10 \mathrm{~Hz})$.

Figures 15 and 16 show unreinforced pavement vertical settlement response contours applying two different loading durations and frequencies for the same pressure amplitude.

The differences in the response contours are clear although the pressure amplitude is the same for both cases.

Figure 17 shows vertical settlement profile versus time at different dynamic loading amplitudes for unreinforced pavement. It can be seen that vertical settlement increases with the increase in stress amplitude values.

Figure 18 shows settlement response history for one-layer reinforced pavement and unreinforced system. No significant difference is noticed between the two cases. Effect of loading frequency on vertical settlement response is significant only for high stress amplitudes as shown in Figure 19.

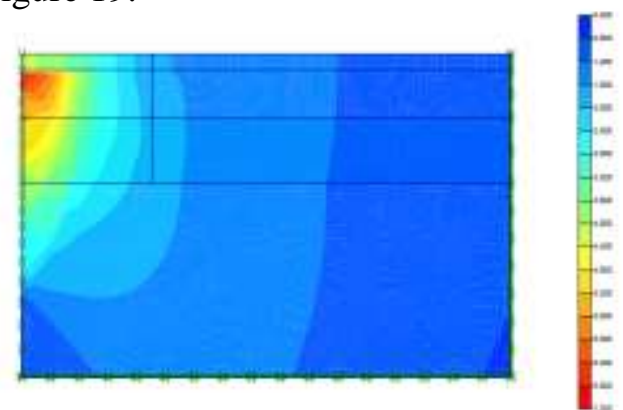

Fig. 16. Vertical settlement contours for load amplitude $400 \mathrm{kPa}, \mathrm{t}=0.2 \mathrm{~s}(\mathrm{f}=2.5 \mathrm{~Hz})$

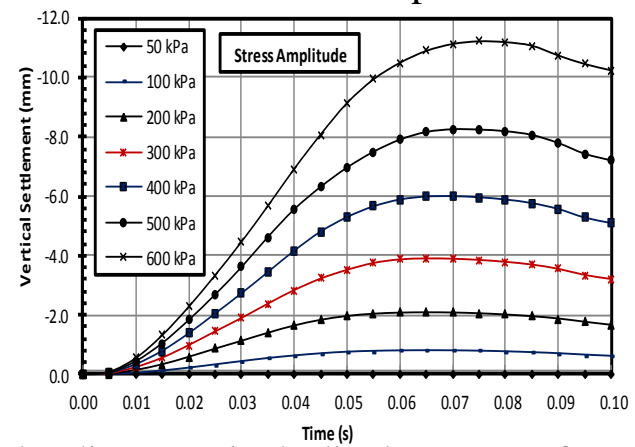

Fig. 17. Dynamic loading vertical displacement for unreinforced pavement (frequency $=10.0 \mathrm{~Hz})$ 


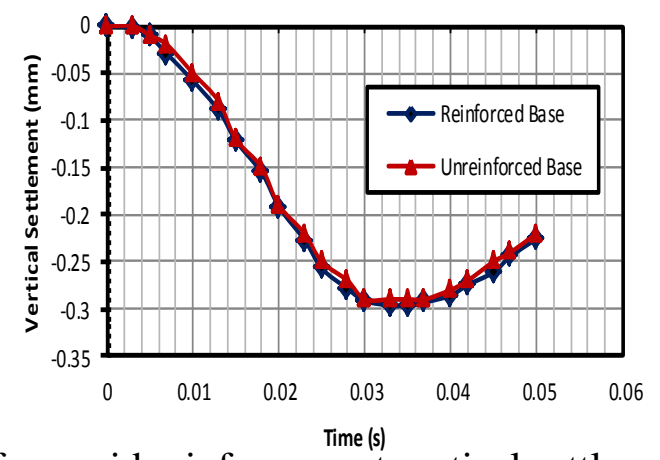

Fig. 18. Effect of geogrid reinforcement vertical settlement response history.

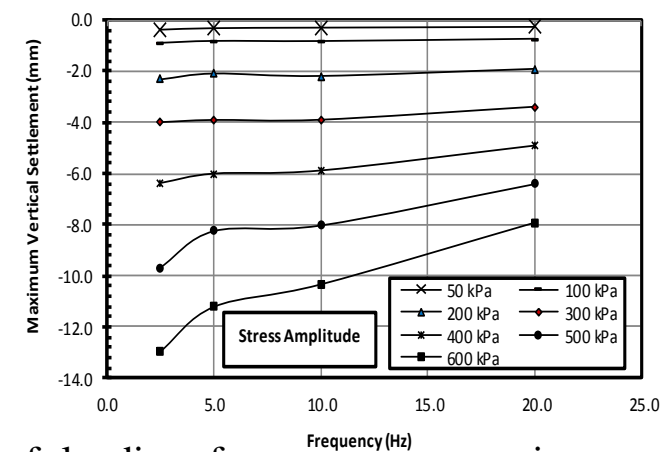

Fig. 19. Effect of loading frequency ${ }_{\text {Frequenc( }(\mathrm{Hz})}$ maximum vertical settlement for dynamic loading.

\section{Conclusions}

A series of FE simulations have been carried out to evaluate the benefits of integrating a high modulus geogrid into the pavement foundation. For the materials and loading conditions used, the following conclusions can be drawn:

1. A significant improvement in pavement behavior is obtained by applying one-layer of geogrid reinforcement. Vertical displacement and effective stress responses are significantly lower for reinforced pavement system.

2. Effect of geogrid axial elastic stiffness is on reinforced pavement behavior is not significant.

3. No significant improvement in pavement system was gained by adding another layer of geogrid to the pavement system.

4. For case of dynamic loading, no significant influence of geogrid reinforcement on pavement behavior was observed.

5. Effect of dynamic loading frequency on pavement behavior is significant only for high stress amplitude.

\section{REFERENCES}

[1] Pandey, S., Rao, K. R. and Tiwari, D.( 2012).” Effect of Geogrid Reinforcement on Critical Responses of Bituminous Pavements.", 25th ARRB Conference - Shaping the future: Linking policy, research and outcomes, Perth, Australia.

[2] Howard, I.L. and Warren, K.A. (2009). "Finite-element modelling of instrumented flexible pavements under stationary transient loading." J. Transportation Eng. ASCE, 135(2): 53-61. 
[3] Perkins, S. W. (2001). "Mechanistic-empirical modeling and design model development of geosynthetic reinforced flexible pavements." Montana Department of transportation, Helena, Montana, Report No. FHWA/MT-01-002/99160-1A.

[4] Perkins, S. W. (2002). "Evaluation of geosynthetic reinforced flexible pavement systems using two pavement test facilities." Report No. FHWA/MT-02-008/20040, U.S. Department of Transportation, Federal Highway Administration.

[5] Berg, R. R., Christopher, B.R., and Perkins, S.W. (2000). "Geosynthetic reinforcement of the aggregate base course of flexible pavement structures." GMA White paper II, Geosynthetic material Association, Roseville, MN, USA, 130 p.

[6] Perkins, S. W., Ismeik, M. and Fogelsong, M. L. (1999). "Influence of geosynthetic placement position on the performance of reinforced flexible pavement systems." Proceedings of the Conference Geosynthetics '99, Boston, MA, USA, Vol. 1, pp. 253-264.

[7] Barksdale, R.D., Brown, S.F., and Chan, F. (1989). "Aggregate base reinforcement of surfaced pavement" Geotext. Geomembrane, 8, pp.165-189.

[8] Virgili, A., Canestrari, F., Grilli, A. and Santagata, F.A. (2009). "Repeated load test on bituminous systems reinforced by geosynthetics." Geotextiles and Geomembranes Vol. 27, pp.187-195.

[9] Dondi, G., (1994). "Three-dimensional finite element analysis of a reinforced paved road." Proceedings of the Fifth International Conference on Geotextiles, Geomembrane and Related Products, Singapore, pp. 95-100.

[10] Moayedi, H., Kazemian, S., Prasad, B. and Huat (2009). "Effect of Geogrid Reinforcement Location in Paved Road Improvement.” Journal of EJGE, Vol.14, pp.3313-3329.

[11] Miura, N., Sakai, A., Taesiri, Y., Yamanouchi, T. and Yasuhara, K. (1990). "Polymer grid reinforced pavement on soft clay grounds." geotextiles and geomembranes, Vol. 9, No. 1, pp. 99-123.

[12] Wathugala, G. W., Huang, B., and Pal, S. (1996)."Numerical simulation of geosynthetic reinforced flexible pavement." Transportation Research Record 1534, Transportation Research Board, national Research Council, Washington, DC, USA, pp.58-65.

[13] Leng, J., Gabr, M. A., 2005. "Numerical analysis of stress-deformation response in reinforced unpaved road sections." Geosynthetics International, Vol.12, No.2, pp.111-119.

[14] Nazzal, M. D., Abu-Farsakh, M. Y. and Mohammad, L. N. (2010). "Implementation of a critical state two-surface model to evaluate the response of geosynthetic reinforced pavements." International Journal of Geomechanics, Vol. 10, No. 5, p202-212.

[15] Plaxis B. V. (2004). Plaxis 2D Version 8.2, Finite element code for soil and rock analysis, A. A. Balkema, Delft, Netherlands.

[16] Kazemian, S., Barghchi, M., Prasad, A., Maydi, H. and Huat, B.K. (2010). "Reinforced pavement above trench under urban traffic load: Case study and finite element (FE) analysis." Journal of Scientific Research and Essay Vol. 5 (21), Nov.4, 2010, pp. 3313- 3328. 


\section{النمذجه ثنائية الأبعاد بإستخدام العناصر متناهية الصغر للرصف الأسفلتى المسلح بالثبك الصناعلى الصناعى}

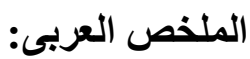

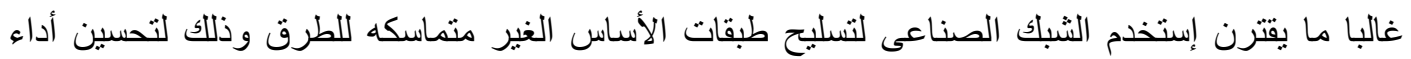

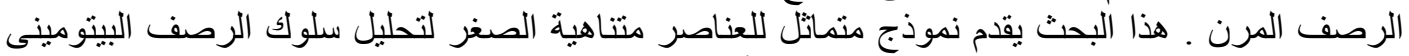

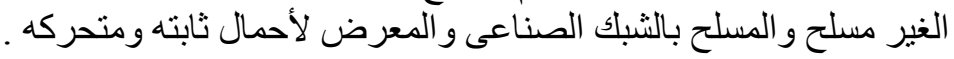

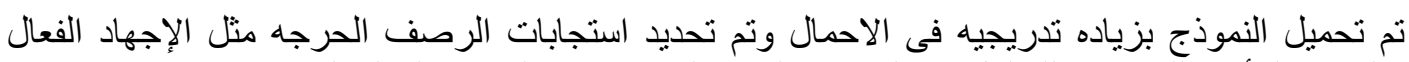

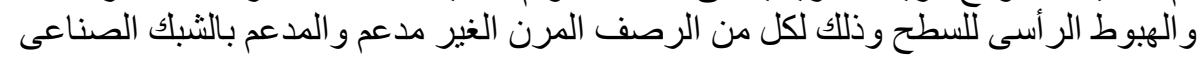

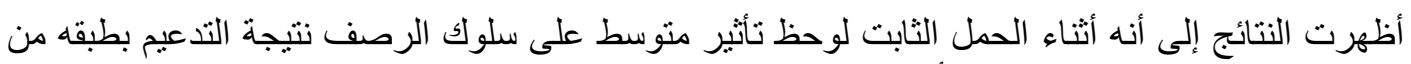

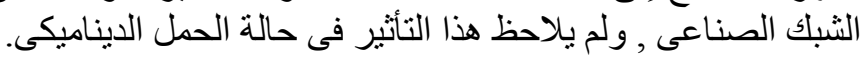
كان تأثير تردد الحمل الديناميكى ملحوظ على هبوط الرصف ولئ وخصوصا عند ذروة الأحمال العاليه.

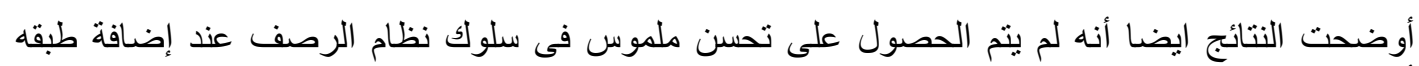

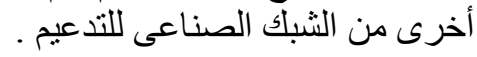

